\title{
A Voz no Tratamento Psicanalítico Das Psicoses
}

Fernanda Mara da Silva Lima1

\section{RESUMO}

Este artigo tem por objetivo pensar a especificidade do tratamento psicanalítico da psicose no que se refere ao saber fazer com lalangue em que coloca em cena a articulação entre letra e voz. Para tanto será apresentada a premissa de que a voz é causa e efeito do sujeito a partir da constituição do sujeito pelas operações lógicas de alienação e separação. Também será trabalhado outro modo de pensar a estruturação do sujeito que se baseará pela articulação entre linguagem, lalangue e letra. Isto posto para em seguida verificar a particular relação do sujeito psicótico com a voz enquanto objeto a.

PalavRas-Chave: Psicanálise, psicoses, tratamento, objeto, voz.

\footnotetext{
${ }_{1}^{1}$ Professora Substituta da Universidade Federal Fluminense. Doutora em Teoria Psicanalítica pela Universidade Federal do Rio de Janeiro. Mestre em Pesquisa e Clínica em Psicanálise pela Universidade do Estado do Rio de Janeiro. Especialista em Saúde Mental Pelo Instituto de Psiquiatria da Universidade Federal do Rio de Janeiro em parceria com a Secretaria Municipal de Saúde do Rio de Janeiro. E-mail: fernandamaralima@yahoo.com.br
} 


\section{A Voz Na Constituição Do Sujeito}

É com Lacan que sustentamos a importância de se pensar a voz na constituição do sujeito:

Tudo o que o sujeito recebe do Outro pela linguagem, diz a experiência comum que ele o recebe como forma vocal. A experiência de casos [...] mostra que existem outras vias que não as vocais para receber a linguagem. A linguagem não é vocalização. Vejam os surdos. [No entanto, há] uma relação que liga a linguagem a uma sonoridade (LACAN [2005(1962-1963)], p. 298-9).

A linguagem não consegue todo o campo abarcar, algo escapa. Como a voz extrapola ao simbólico, então a linguagem não é vocalização. No entanto, a voz do Outro transmite a linguagem para o infans. Devemos, portanto, enfatizar a especificidade inerente ao objeto voz, ele é signo do Desejo do Outro.

(...) o objeto a é diretamente implicado quando se trata da voz e isso no nível do desejo. Se o desejo funda-se como desejo do Outro, esse desejo enquanto tal manifesta-se no nível da voz. A voz não apenas o objeto causal, mas 0 instrumento pelo qual se manifesta o desejo do Outro. (LACAN [1965-66] apud VIVĖS, J-M, 2009a, p. 194).

No Seminárioz em que aborda a pulsão específica do objeto voz, a pulsão invocante, Lacan convida Alain Didier-Weills para falar. Isso se deve ao fato de Lacan reconhecer a importância do trabalho deste psicanalista com a musicalidade presente na relação entre o infans e o Outro materno.

A musicalidade da voz materna opera como via de transmissão da linguagem para o futuro sujeito, pois articula duas funções, a materna e a paterna; trata-se de uma operação que consiste em articular num só golpe o continuum e o corte. A musicalidade da voz da mãe foi nomeada de sonata materna por Quignard, lembrando que sonata é um termo do campo musical.

O laço entre a criança e a mãe, o reconhecimento de um pelo outro, depois a aquisição da linguagem materna se criam no seio de uma chocagem sonora muito ritmada datando antes do nascimento, prosseguindo depois do parto, se reconhecendo pelos gritos e vocalizes, depois pelas canções e versinhos, nomes e apelidos, frases repetidas, que coagem, que se tornam ordens (QUIGNARD apud MATTOS-AVRIL, 2011, p. 71).

2 Seminário XXIV, L'insu que sait de l'une bévue s'aile à mourre.

$3 \mathrm{Na}$ tradição freudiana, temos outros autores que se dedicarão à música e à musicalidade, como por exemplo Reik, que será por Lacan citado no Seminário 10 quando da elaboração conceitual do objeto voz. 
Nesta mesma direção, Didier-Weill afirmará que o bebê recebe a sonata materna pela musicalidade, pelo "canto", que transmite a continuidade pelas vogais e a descontinuidade através das consoantes, sem qualquer filiação ao sentido ou aos significados.

\begin{abstract}
A música da voz materna faz traço: é ritmo musical que introduz o bebê na alternância presença-ausência do Outro. A primeira manifestação da instância do Outro pré-histórico - das Ding - é sua transmissão como ritmo musical. O significante originário é transmitido ao infans pelo Outro musical (voz da mãe). Como as palavras da sonata materna não são ainda portadoras de sentido, elas transmitem ao infans sua pura significância musical, isto é, uma estrutura sonora feita de diferenças matemáticas diacrônicas e sincrônicas (CATÃO, 2009a, p. 13-14).
\end{abstract}

Ritmo em que se inscreve a presença e ausência é a marca do corte que produz descontinuidade no continuum. Aí incide a transmissão da linguagem veiculada pela musicalidade da voz da mãe, que também porta a voz do pai.

Também devemos nos reportar a Freud (1923 [1996]), que dirá com contundência que a mãe enquanto função dirige a seu bebê os primeiros ditos que são antes de mais nada marcas acústicas. Em sintonia com esta formulação, Alain Didier-Weill (1976 [1997]) sustentará a tese de que o traço unário está condicionado à nota da voz da mãe.

Vivès (2012) enfatiza o papel da voz do Outro materno na constituição do sujeito enquanto transmissor da linguagem, sendo por esta via que ocorre o processo de subjetivação. É desta forma que podemos entender a célebre afirmativa lacaniana de que a pulsão invocante é "a mais próxima da experiência do inconsciente" (LACAN, 1964/1988, p. 102).

Na esteira da constituição do sujeito, devemos articular Behajung e Austossung de Freud (1925 [1996]) com a alienação e a separação de Lacan (1964 [1998]). JeanMichel Vivès (2009a), ao abordar a formalização dos tempos lógicos da constituição do sujeito, sustenta a tese de que, no primeiro tempo, haveria a alienação do bebê à musicalidade da voz da mãe. E o segundo tempo lógico da operação de causação do sujeito, a separação, só seria possível a partir de um ensurdecimento para a voz do Outro, como cicatriz do recalque primário. É o que Jean-Michel Vivès (2009a \& 2012) nomeou de ponto surdo, que se obtém a partir de uma metáfora4. A constituição da voz enquanto objeto pulsional resultará das operações de alienação e separação donde se extrai um resto, o objeto $a$. 
Num primeiro momento, a musicalidade da voz da mãe convida à alienação, pura continuidade, e, portanto, será necessária outra operação, logicamente posterior, para que se produza um corte donde advirá a separação que resultará na queda do objeto pequeno a. Dentre as formas de apresentação do objeto a, destaco a voz5.

A voz enquanto objeto a é este objeto extraído do campo do Outro (LACAN, 1962-1963 [2005]). A voz recebe o estatuto de objeto original por se situar no campo da causação do sujeito e, desta forma, remete à relação do sujeito ao próprio âmago do Outro. Por isso se diz que a voz dá notícias de que o Outro não é uma miragem (LACAN, 1962-1963 [2005]). Além disso, a voz é considerada objeto essencial na medida em que coloca em cena a relação do sujeito com o desejo do Outro, uma vez que a voz é signo do desejo do Outro.

Portanto, o advento do sujeito é uma resposta à invocação do Outro (CATÃO, 2015). O que está em consonância com a afirmação de que a voz tem um papel fundamental na constituição e no funcionamento do laço com a alteridade (CATÃO, 2009).

\section{Modo Outro De Pensar O Sujeito Em Sua Constituição: lalangue, LINGUAGEM E LETRA}

Lacan nos advertirá enfaticamente de que, para o infans, a linguagem de início, ela não existe. A linguagem é uma elocubração de saber acerca de lalangue6. E para pensar sobre a relação entre inconsciente e lalangue, Lacan dirá: "Não é porque o inconsciente é estruturado como uma linguagem que lalangue não tenha que 'jogar' (jouer) contra seu gozar, já que ela é feita desse próprio gozar" (LACAN, 1974, p. 7). Pode-se afirmar então que o inconsciente é estruturado como uma linguagem a partir das marcas prévias de lalangue. Assim é que o inconsciente, com suas leis próprias inscritas na metáfora e na metonímia, seria um saber-fazer com lalangue.

${ }_{5} \mathrm{Na}$ lista de objetos pulsionais, há outros três, a saber, seio, fezes e olhar. No entanto, enfatizo a voz pelo recorte deste trabalho.

6 Este neologismo surgiu de um ato falho em que Lacan ao se remeter ao Vocabulário de Psicanálise de Laplanche e Pontalis deslizou para Vocabulário de Filosofia, Lalande. Trata-se da fusão entre o artigo (la) e o substantivo (langue) que produziu lalangue. O termo surgiu desta forma no Seminário $O$ saber do psicanalista (1971-1972). 
O inconsciente é algo do qual a linguagem não consegue todo o campo abarcar. Disso decorre o fato de que o que não foi simbolizado retorna no real. No campo da neurose temos o testemunho do que comparece nos sonhos, nos atos falhos, nos lapsos, nos chistes, nas formações do inconsciente.

O inconsciente é o testemunho de um saber enquanto ele escapa em grande parte ao ser, que dá ocasião de perceber até onde vão os efeitos de lalangue. Com efeito, é verdade que esse ser responde por todo tipo de afetos que ficam enigmáticos, o que resulta dessa presença de lalangue, pois, no que se refere ao saber, ela articula coisas que vão muito mais longe de tudo o que ele mesmo sustenta a título de saber enunciado. (LACAN, 1972-73, p. 190).

Lalangue são os primeiros significantes passados ao infans pelo Outro materno, por isso "lalangue é dita materna". Significantes recebidos do Outro sem que isso resulte numa compreensão (LACAN, 1975-1976). Lalangue é um depósito de significantes oriundo do campo do Outro. São os detritos da língua falada pelo Outro, restos que aprisionam e deixam marcas no corpo do sujeito.

Estes primeiros significantes recebidos do Outro não se articulam e não se reduzem a uma unidade. Não se trata de S1-S2, mas sim de uma série de significantes Uns. S1(S1(S1)S1-S2) é um enxame zumbidor. É interessante destacar que S1 faz homofonia em francês com essaim; Lalangue consiste num enxame (essaim) de significantes (S1) que não se encadeiam entre si. (LACAN, [1972-1973], p. 196).

"O Um encarnado de lalangue é algo que resta indeciso entre o fonema, a palavra, a frase, mesmo todo o pensamento. É o de que se trata no que chamo de significante-mestre" (LACAN, 1972-3: 196). O Significante Um é o significante-mestre a partir do qual a cadeia será articulada. O significante vai trabalhar com lalangue para extrair um conceito de linguagem, como sublinha Lacan: "É totalmente certo que algo voltará a surgir nos sonhos, em toda a sorte de tropeços, em toda sorte de maneiras de dizer, em função da maneira pela qual lalangue foi falada e também escutada por cada um em sua particularidade" (LACAN, 1974, p. 126).

Desta citação enfatizo o fato de que lalangue foi falada e escutada pelo sujeito na sua singularidade. Isto posto para destacar que Colette Soler dirá que estes significantes são do campo sonoro e são recebidos pelo ouvido (SOLER apud BERNARD \& DELAPLACE, 2014).

E em sintonia com esta ideia, é preciso citar Lacan para enfatizar a potência musical do significante enquanto sonoro e acústico: 
sequência, bem como à suspensão de seu valor, a cada instante, no advento de um sentido sempre pronto a remissão, ou conforme se acomode na fala à modulação sonora, uma dada finalidade de análise acústica: tonal ou fonética, ou até mesmo de potência musical (LACAN, [(1955-1956) 1998], p. 538-539).

Em “Excursus", Lacan (1973-1978) afirmará:

A linguagem é o acúmulo de gozo (...) efeitos de chuva, efeitos de ravinamento... (...) e se vocês me permitem um jogo de palavras que 0 francês permite: é que isso que nós tocamos, isso que a experiência nos deixa nas mãos desde o tempo em que isso se passa, é o escrito-vão (écritvain), mas em duas palavras (LACAN, 1973-1978, p. 83)7.

Podemos pensar que é crit-vain abre a uma dupla leitura: escritor e escrito-vão. A relação sexual, por não existir, torna a escrita vã. É assim que se diz que a escrita do sujeito, sua escrita pulsional, não cessa de tentar se escrever. Por isso e não por outra coisa que a escrita é vã, no entanto, necessária8, pois não pára de se escrever.

Não é por isso que o que se escuta como chuva de significantes, e que não cessa de não se escrever, impõe ao sujeito uma escrita?

$\mathrm{Na}$ "Conferência de Genebra sobre o sintoma", Lacan afirma que lalangue é "um coador que se atravessa, por onde a água da linguagem chega a deixar algo na passagem, alguns detritos9" (LACAN, 1975 [1988], p. 15). E com estes depósitos e detritos cada um terá que se virar. Por isso podemos escutar de uma criança muito pequena palavras como "talvez", "ainda não" sem que ela ainda formule uma frase inteira. Estas palavras foram escutadas, mas não compreendidas.

Lacan (1974) também apresenta a formulação de que lalangue não é sem letra. Sobre este ponto, Porge (2013) nos aponta que a metáfora do depósito nos indicaria o caminho para a articulação entre lalangue e letra.

Para avançar na questão colocada por Lacan de como a lalangue pode precipitar a letra, cito Porge:

7 Tradução realizada por Renata Mattos-Avril.

Agora cito Lacan, em francês: "Le langage est toute accumulation, ce cumulus de jouissance que j'ai évoquée ce matin et qui semble concentré comme sur des pointes, des pies..., enfin, il y a aussi des effets de pluie, des effet de ravinement, n'est-ce pas, dans cet ordre... dans cet ordre, si vous me permettez un jeu de mots que permet le français: c'est que ce que nous touchons, ce que l'expérience nous laisse dans la main depuis le temps que ça se passe, c'est l'écrit-vain mais en deux mots" (LACAN, 1973, p. 83)

8 Lacan recorrer a à lógica aristotélica para abordar o possível, impossível, contingente e necessário. 9 Na versão em espanhol: "(...) una criba que se atraviesa, a través de la cual el agua del lenguaje llega dejar algo tras su passo, alguns detritos (...)" (LACAN, [1975-1988]: 129). 
Talvez a resposta se encontre na Conferência de Genebra sobre o sintoma: Lacan recorre à metáfora do coador (...) que peneira o escoamento da água da lalíngua, depositando os detritos, os pedaços de significantes aos quais a linguagem se amarra, o coador causando as precipitações de letras, de traços unários na lalíngua. A passagem de uma língua a outra, o passe, seria variações do coador da letra, que por seus buracos deixa passar o Um, o S1, o traço unário incarnado na lalíngua e que continua indeciso entre fonema, palavra, frase ou em todo pensamento, este Um que o pedaço de barbante de um nó borromeu suporta (PORGE, 2013, p. 59).

Segundo Porge, a letra aparece e se apresenta no que resta da chuva de linguagem, nos seus detritos, no que se deposita e se acumula a partir de lalangue.

Em "Lituraterra", Lacan (1971) dissocia letra de significante. Neste momento teórico, a letra aponta para o real, enquanto o significante remeteria ao simbólico. A metáfora de litoral será apresentada para localizar uma marca entre dois campos heterogêneos, descontínuos, os registros real e simbólico. Lacan nos adverte de que não se trata de uma fronteira, já que os territórios não são de uma mesma natureza. Incidiria aí uma ruptura radical entre estes dois campos.

Lacan indica que letra circunscreve o furo no saber, e é desta forma que letra faz litoral entre real e simbólico, entre saber e gozo. Segundo Andrea Guerra: "A letra escreve a radicalidade da diferença de consistências entre saber, elucubração em torno da verdade, e gozo, desfrute do que essa verdade tem de inacessível". (GUERRA, 2007, p. 81).

Se letra faz borda entre saber e gozo, então a questão que se coloca é como pode a linguagem tocar algo do gozo. Respondemos que esta operação existe e coloca em cena a possibilidade de localizar, reduzir, enxugar o gozo. O banho da linguagem proveniente do campo do Outro possibilitará a chuva de significantes, e, a partir disso, será necessário que cada um lide com os detritos que restaram desta chuva. É por isso que chamamos de enxugamento de gozo esta operação cunhada pela letra. Letra é cifra de gozo.

(...) a letra pensada como distinta do significante, seria o que, na ordem da linguagem, permitiria apreender a circulação dessa substância, dessa materialidade à qual Lacan gradativamente associa ao gozo (...).

A promoção da letra em detrimento do significante vem indicar que este, por si, não responde por tudo que pode estar em jogo na experiência de uma análise. No nível do significante, por exemplo, jamais seria possível perceber a natureza de fetiche das cartas enviadas por Gide a Madeleine, pois sua dimensão de fetiche não estava no conteúdo das cartas, mas no valor que tinham para Gide, para além das mensagens veiculadas. Como, no entanto, articular essas duas dimensões da lettre, como associar sua dimensão significante, mensageira, àquela que se traduz em sua materialidade, independente do sentido veiculado? (MANDIL, 2003, p. 47-48). 
Em “Lituraterra”, Lacan (1971) define letra por duas funções: uma escrita lógica e o efeito dos significantes. A letra e o significante são consequências da chuva de linguagem. Litura aponta para resto, dejeto, lixo. Joyce, por equívoco homofônico, partiu-se de letra (letter) para lixo (litter), e Lacan disso se serviu para "literaturar", no sentido de apontar para o trabalho de fazer algo com o resto. Resto que cai do que resulta das operações lógicas da constituição do sujeito, objeto lacaniano pequeno $a$.

Em linhas gerais, é importante destacar que cada sujeito terá que se arranjar com o que restou da chuva de significantes e, portanto, será preciso um trabalho de cada sujeito com os significantes e o gozo de lalangue na tentativa de produzir uma diferenciação entre os significantes e uma localização de gozo. E é disso que se trata o saber-fazer com lalangue. Lacan (1974) afirma que lalangue civiliza o gozo. Tratase de uma operação que produz escoamento do excesso de gozo, localizando-o nos objetos destacados do corpo, os objetos pequeno a, que, dentre suas formas de apresentação, destaco a voz.

\section{A Voz Nas Psicoses}

Voltemos ao tema da constituição do sujeito para colocar em pauta a especificidade do campo da psicose e do autismo. A sonata materna transmite a linguagem, pois a voz da mãe também veicula a voz do pai. Além disso, algo resta das operações lógicas de causação do sujeito, o objeto, designado por Lacan de pequeno $a$, que, dentre suas formas de incidência, destaco a voz. Por isso é que Vivès (2012) afirma que a voz é causa e efeito do sujeito.

Das operações lógicas de constituição do sujeito, a alienação e separação, algo se perde, o objeto designado por Lacan de pequeno a. Esta é formalização concernente ao campo da neurose. Então o que se passa nas psicoses?

Primeiramente devemos esclarecer que não poucos analistas irão supor uma aproximação entre autismo e esquizofrenia, de modo que o autismo pertenceria, assim como a esquizofrenia, ao campo das psicoses. Alguns dos trabalhos que podemos citar a esse respeito são os de Baio (1993), Bruno (1999), Soler (2002), e Lacan (1975/1988). 
Os impasses na constituição do sujeito decorrem em tempos diferentes no que se refere às psicoses e no que se refere ao autismo. $O$ autismo apresenta uma grave problemática na alienação enquanto as psicoses apresentam impasses no tempo lógico da separação. Ainda assim, gostaríamos de defender o autismo no campo das psicoses, pois nos interessa pensar a não extração de objeto. Esta questão é colocada tanto para os psicóticos quanto para os autistas, guardadas as devidas particularidades10. O psicótico e o autista não cunham, portanto, um ensurdecimento frente ao Outro.

\begin{abstract}
Propomos que há dois tipos de não surdez: o não ensurdecimento absoluto do autista - que escuta barulhos - e o não ensurdecimento relativo do psicótico - que ouve as vozes reais da alucinação verbal. O autista é hipersensível ao barulho exatamente porque ele não é surdo. Os barulhos para ele não são diferenciados. Ele não é capaz de atribuir um sentido a tais barulhos, e é por esta razão que o autista os teme (CATÃO \& VIVĖS, 2011, p. 86-87).
\end{abstract}

Vivès (2013) esclarece que o neurótico constituiu o "ponto surdo" que se instaura com o recalque originário permite fazer cair o objeto enquanto que o psicótico o carrega no bolso. É o mesmo que afirmar que o psicótico mantém uma aproximação maior com o objeto.

Os homens livres, os verdadeiros, são precisamente os loucos. Não há demanda de pequeno a, seu pequeno a, ele o tem, é o que ele chama de vozes, por exemplo. (...) Ele não se situa no lugar do Outro pelo objeto a, o a, ele o tem a sua disposição. (...) ele tem a sua causa em seu bolso (LACAN, 1967a, p. 13)11.

Se este objeto está demasiadamente próximo, é preciso um trabalho do sujeito para mantê-lo à distância. Freud, quando se dedicou ao estudo das Memórias de Daniel Paul Schreber, afirmou que o tocar piano e recitar poesias, por exemplo, são maneiras que Schreber encontrou de dar algum tratamento às vozes (VIVÈS, 2013).

Além dessas estratégias, Schreber recorre a algumas outras, como falar forte e produzir ruídos altos na tentativa de abafar as vozes, além da rememoração de poemas. (BERNARD \& DELAPLACE, 2014).

10 Sobre este tema, remeto a leitura de Soler (2002), Vivés e Catão (2011). No entanto, como nosso foco não é a especificidade no processo de constituição do sujeito para cada apresentação clínica, deixaremos este ponto para ser desenvolvido num próximo trabalho.

11 Tradução realizada por Núria Muñoz em sua tese (2005). Cito agora o original em francês: "les hommes libres, les vrais, ce sont précisément les fous. II n'y a pas de demande du petit a, son petit a il le tient, c'est ce qu'il appelle ses voix, par exemple. (...) II ne tient pas au lieu de l'Autre, du grand Autre, par l'objet a, le a il l'a à sa disposition. (...) qu'il a as cause dans as poche" (LACAN, 1967a, p. 13).

Psicanálise \& Barroco em revista | v.17, n. 3 | dezembro de 2019 
O radinho colocado ao ouvido tem a mesma função. Segundo Vivés (2013), trata-se de um artifício para dar a esta voz sem origem um lugar específico, alguma possível localização.

O trabalho do sujeito para viabilizar um possível afastamento deste objeto demasiadamente próximo de modo a produzir alguma possível modulação. E é neste sentido que a articulação entre letra e voz com um certo saber-fazer com lalangue direciona o tratamento psicanalítico da psicose.

\section{Uma Direção De Tratamento Psicanalítico}

Para pensar sobre o trabalho do analista, cito Lacan: "que é d'alíngua que se opera a interpretação" (LACAN, 1974, p. 52). Foi com o conceito de lalangue que surgiu a tese de lalangue de transferência na psicose. Desta forma, não seria o sujeito suposto saber o motor da transferência na psicose, mas sim lalangue.

Lalangue rompe com a significação e o sentido, apontando para a equivocidade. Lacan (1975, p. 11-12), na "Conferência de Genebra sobre o sintoma", afirma que "Não é absolutamente ao acaso que na lalangue, qualquer que seja ela, na qual alguém recebeu a primeira marca, uma palavra é equívoca12". Em "O Aturdito", Lacan (1972) afirma que a interpretação deve ser a partir da equivocidade. A equivocidade guarda uma aproximação com a ressonância na medida em que reverbera, desliza e produz ecos.

Vale enfatizar o afastamento do sentido quando da afirmativa lacaniana de que "a interpretação analítica não é feita para ser compreendida; ela é feita para produzir ondas" (LACAN, 1975-1976, p. 40). Provocar ondas consiste em fazer ecos, ressonâncias e equívocos. No "Seminário 24, L'insu que sait de l'une bévue s'aile à mourre", na lição da aula de 19/04/1977, e também no "Seminário 23 - O Sinthoma", encontramos correspondência para a ideia de que a interpretação deve operar a partir do equívoco fazendo ressoar algo para além do sentido.

12 LACAN, J. Conferencia en Ginebra sobre el Síntoma (1975). Citemos a versão em espanhol: "Para nada es un azar que en lalengua, cualquiera sea ella, en la que alguien recibió una primera impronta, una palabra es equívoca". 
Sobre a formulação lacaniana de que "o significante pode ser reduzido a uma torção de voz, um equívoco" (LACAN, 1975-1976 [2007], p. 92), Maurício Maliska (2015) indica que esta "torção" pode apontar para "chiffonnage", citada por Lacan no Seminário 24. Chiffoner seria "amarrotar", "enrugar", "comprimir", "enrugar", "estropiar". É preciso torcer a voz para daí extrair um significante novo. Não é mais um significante dentre outros; e sim um significante outro que rompe com a cadeia e, portanto, não faz série.

Trata-se de apontar para o furo do significante na linguagem, para sua impossibilidade de significar. Lacan rompe com a identidade fonatória da linguagem e propõe que a interpretação seja poética. Mas de que poesia se trata? Deveria ser o psicanalista um poeta?

“(...) a poesia (...) é efeito do sentido, mas igualmente efeito de furo. Não há senão que poesia, eu lhes digo, que permite a interpretação, é nisso que chego mais, em minha técnica, a isso que ela tem; eu não sou bastante poeta, eu não sou poeta bastante" (LACAN, [1976-1977], p. 4).

O trabalho psicanalítico inspirado pela poesia se despede do sentido e mantém sua filiação à equivocidade e à ressonância fazendo "entreouvir" a imaterialidade da voz. A poesia faz metonímia reverbera produzindo ecos. A poesia visa o efeito do furo e não o sentido.

\section{Fragmentos De Um Caso Clínico}

Apresentarei fragmentos de um trabalho por mim conduzido com uma criança de 6 anos, que chamarei de Leci, e sua mãe, Vera13.

Minha posição é aquela que Lacan nos alertou de secretariar o trabalho do sujeito e sustentar uma "submissão completa ainda que advertida às posições propriamente subjetivas do paciente" (LACAN, 1955-1956, p. 540), o que me parece estar em sintonia com as coordenadas de Freud (1912) em manter a atenção flutuante, senão nada encontraríamos além do já sabido.

${ }_{13}$ Trabalho clínico que me remete ao trabalho teórico, em consonância com a afirmativa freudiana (1912) de que em psicanálise a atividade de pesquisa e tratamento coincide. Deste modo, remeto a leitura de um artigo de minha autoria (Lima, 2011), intitulado: "Sobre um tratamento psicanalítico da psicose". Nesta ocasião pude tratar de outros apontamentos teóricos a partir do trabalho clínico com Leci e Vera. 
$\mathrm{Na}$ ocasião em que procurou tratamento para sua filha, Vera se encontrava num momento de extrema dependência de outras pessoas. Relata que não conseguia fazer nada sozinha e explica que necessitava da ajuda de outras pessoas (familiares ou a empregada) para ir ao banco, cuidar da casa e também para ficar com sua filha. Conta que a maternidade foi um grande marco em sua vida e localiza aí o início do que nomeou de "transtorno do pânico". Explica que, antes da maternidade, era uma pessoa independente, tinha autonomia. "Eu trabalhava e fazia as minhas coisas".

Vera relatava que era muito difícil sair com Leci de casa e por isso demorou cinco meses para levá-la ao tratamento. E, quando Leci chegou, foi para o colo da psiquiatra $14 \mathrm{e}$ fazia um movimento em que parecia se embalar. Também mexeu rapidamente em alguns brinquedos e objetos. Por imaginar que sua filha gritaria, morderia e quebraria as coisas e que sequer entraria na sala, Vera ficou surpresa e disse: "Ela não brinca assim comigo. Aliás, eu também não tenho paciência!... Eu não suporto ela e só brinco com o cachorro de minha irmã".

Vera contou que não aguentava ficar perto de sua filha, pois Leci gritava, chorava, gemia e lhe machucava muito. Fiz uma intervenção interrogando sobre o que se passava com Leci. Vera, intensamente irritada disse: "Como assim o que está acontecendo com ela? Não faz sentido! Nada do que ela faz tem sentido. Ela ri e chora ao mesmo tempo. É uma esquizofrenicazinha. Ela é um muro! Nada tem sentido!".

A irritabilidade de Vera diante da convocação para falar de sua filha é o que promoveu o reposicionamento da analista por reconhecer nesta irritabilidade um ponto de impossibilidade da mãe.

Tomei outra direção de trabalho, em que legitimava que o ponto de maior incômodo para Vera era as agressões que sofria da filha e, a partir daí, seria então necessário construir uma maneira de se proteger. Não se tratava mais de convocar Vera a falar sobre qual sentido teria o que se passava com sua filha.

Uma menina, que desde bebê grita e chora sem parar, era o que Vera podia falar sobre Leci. Não havia um enunciado que mostrasse as preferências de sua filha, seja na alimentação ou mesmo nas brincadeiras. Não havia uma história a contar sobre esta menina que estava desta forma anônima no desejo de sua mãe. Leci era

14 Este trabalho ocorreu num serviço de tratamento em que a equipe também era composta por psiquiatra. 
um "muro" que nada do que fizesse tinha sentido, além de gritar e chorar sem parar desde bebê.

Quando a criança satura a falta materna, obtém para si um lugar de horror. A criança se torna um campo estrangeiro para sua mãe, já que o grito, por não ter sido convertido em apelo, não cavou um lugar para esta menina. Se "a fala só é fala na medida em que alguém nela crê" (LACAN, 1953-1954, p. 272), é, portanto, necessário que à criança seja endereçada uma mensagem particularizada. Por isso que não supor um sentido, qualquer que seja ele, ao que se passa com sua filha é o mesmo que manter a ausência de uma mensagem dirigida à filha que a localize como um sujeito, na sua particularidade.

Segundo Stevens (1996, p. 64), "a consequência desta posição para a criança, na qual o desejo do Outro fica ininterrogável, é a ausência de história, ao menos de uma história quanto ao desejo".

Agora vamos nos dedicar ao tratamento de Leci, no qual gostaríamos de destacar quatro tempos de um trabalho com a fala.

Primeiro tempo: Leci tinha um especial interesse pela música da Xuxa. Ela própria procurava pelo DVD e dava indicações de que deveríamos assisti-lo e se embalava junto com o ritmo. No dia em que Leci não encontrou o DVD, machucou a analista com mordidas e arranhões. Foi neste dia que Leci deixou escapar uma palavra: "DVD".

Segundo tempo: Leci enfiava goela abaixo tudo o que estivesse ao seu alcance: bolinha de gude, areia, papel, etc. Eu disse que algumas coisas poderiam ser colocadas na boca, pois não machucavam, e propus que fôssemos até a cozinha do serviço de tratamento para procurar por algo. Ela não só aceitou como começou a levar a analista à cozinha em todos os atendimentos subsequentes. Certa vez encontramos dois tipos de biscoitos na cozinha, nomeando cada um deles, perguntei qual era de sua preferência. "Choco" foi sua resposta.

Terceiro tempo: Vera estava bastante irritada e disse que não aguardaria no serviço o término do atendimento de sua filha. Disse com veemência que não aguentava mais se submeter aos comandos de sua filha. Vera queria retornar depois de uma hora para buscar sua filha, no entanto, para Leci era insuportável que sua mãe ficasse fora do seu campo visual. 
Diante da agressividade de Vera, a analista não conseguiu argumentar a favor da permanência de Vera no serviço. Isso resultou um ato agressivo de Leci endereçado à analista.

Será que a analista encarnou um Outro gozador para Leci? Diante disso, Leci trabalha para descompletá-lo. Um pedaço de carne que vem a faltar no real do corpo da analista. É então no real que Leci realiza o trabalho que não pôde se efetivar simbolicamente.

Neste mesmo dia Leci mostrou-me alguns buracos, como do ralo, e os que apareciam na parede do serviço. Chega inclusive a fazer buracos na parede do serviço. E uma questão se coloca: será que Leci, ao procurar por buracos ou mesmos construí-los, seja no corpo da analista ou na parede, não está realizando um trabalho de tentativa de modulação de objeto? Objeto este que, por não ter caído, está demasiadamente próximo a ela, o que faz com que ela trabalhe arduamente para produzir alguma distância.

Nos próximos encontros, Leci parecia agitada, inquieta. Apresentava movimentos estereotipados, o que para ela era algo bem inédito; além de gritos e mordidas endereçados à analista. A aproximação da analista potencializava este comportamento. E foi neste contexto que Leci se apresentou bastante falante. Uma fala sem sentido que parecia não ter destino, como se nada quisesse comunicar. Um amontoado de significantes sem pausa nem trégua e sem qualquer significação compartilhável.

Se "toda formação humana tem, por essência, e não por acaso, de refrear o gozo" (LACAN, [1967-2003], p. 362), então a produção de Leci deve ser legitimada. Por isso a pontuação da analista foi: "Você está bastante falante hoje, o que será que você quer me dizer?". Leci foi até o muro do serviço e apontou para uma imagem ali desenhada, e disse: "Mar!".

"Muro" remete a algo lalangue materna. Leci aponta para o muro e diante do desenho do mar produziu o som correspondente a imagem. Foi exatamente no ponto de tormento, o "muro", que Leci produziu um revirão, uma reviravolta.

Se para falar é preciso ceder do gozo vocal (Maleval, 2007), então podemos reconhecer o árduo trabalho desta pequena menina em produzir um distanciamento frente a este objeto demasiadamente presente, a voz? 
Retomemos um pouco do percurso de trabalho de Leci para em seguida entramos no quarto tempo. A primeira palavra que surgiu no tratamento foi numa situação de sufoco, momento em que deixar escapar: "DVD". Depois aparece sua segunda palavra quando da escolha de um biscoito, diz: "choco". E a terceira palavra, "mar", apontando para muro.

Quarto tempo: Leci realizava um novo trabalho. Entrava na sala de atendimento e fechava a porta. Quando encontrada, a analista dizia: "Achei você!". A menina saía da sala no meio de muitas risadas e repetia a brincadeira. Até que colocou a analista na sala e fechou a porta e saiu correndo. A analista ia a sua procura novamente e a brincadeira se repetia.

Em dado momento, em meio a correria, passou perto da televisão desligada e olhou fixamente. Sua imagem ali se refletia e então a analista disse: "Olha só ... quem está ali é a..!". E disse seu nome. Depois a própria menina disse seu nome.

Este foi um tempo trabalho em que sua fala era endereçada e se prestava à comunicação. As palavras iniciais de Leci foram "DVD", "Choco" e "Mar". E agora incluía seu nome, e o nome da analista. Inclusive no final dos atendimentos começou a e despedir dizendo: "Tchau, Nanda".

É preciso enfatizar que o trabalho que Leci pôde construir não é sem relação com o trabalho de escuta de Vera. Testemunhamos que Vera pôde reconhecer e legitimar quando sua filha a chamou de mãe. Vera pôde dar significados a atitudes de sua filha, como num dia em que Leci chorou em casa e Vera nos disse que achava que a menina estava com saudades do CAPSi. Esses não seriam alguns exemplos de um novo lugar para Leci no desejo de sua mãe? 


\section{REFERÊNCIAS:}

BAÏO, Virginio. “L`autiste: un psychotique au travail”. In: Preliminaire n. ${ }^{\circ 5}$. Bruxelas: Revue de l'Anthénne 110, p. 68-83. 1993.

BERNARD, David. “A letra e a voz”. In: Revista Trivium - Estudos Interdisciplinares: arte e psicanálise. Ano V. Edição II. 2o semestre de 2013. Disponível em: <http://www.uva.br/trivium/edicoes/edicao-i-ano-v/artigos/a-letra-e-a-voz.pdf >. Acesso em: 17 de maio de 2016. (2013).

BERNARD, David; DELAPLACE Joseph. "Schreber et la musique". L'Information psychiatrique v.90. n.7. pp: 561-566, 2014.

BRUNO, Pierre. "O dito sobre a esquizofrenia”. In: ALBERTI, Sônia. (org.). Autismo e esquizofrenia na clínica da esquize. Rio de Janeiro: Marca d’água Editora, p. 177-196. 1999. CATÃO, Inês. O bebê nasce pela boca: voz, sujeito e clínica do autismo. São Paulo: Instituto Langage. 2009.

. “O corpo como resposta à invocação da mãe”. In: Revista Psicologia, Diversidade e Saúde, Salvador, pp 21-26. 4 (1). 2015.

CATÃO, I. VIVÈS, J-M. (2011). "Sobre a escolha do sujeito autista: voz e autismo". Estudos de Psicanálise. Belo Horizonte. n. 36. p. 83-92. Dezembro, 2011.

DIDIER-WEILL, A. Nota azul. Rio de Janeiro: Contra Capa. (1976 [1997]).

FREUD, Sigmund. Obras completas ESB. Rio de Janeiro: Imago, 1996.

. (1912) "Recomendações aos médicos que exercem a psicanálise”. v. XII.

(1923). “O ego e o Id”, v. XIX.

. (1925) "A negativa", v. XIX. .

GUERRA, Andrea. A estabilização psicótica na perspectiva borromeana: criação e suplência. 2007. Tese (Doutorado em Teoria Psicanalítica) - UFRJ, Rio de Janeiro, 2007.

LACAN, Jacques. (1953-1954). O Seminário, Livro 1: Os escritos técnicos de Freud. Rio de Janeiro, Jorge Zahar Editor, 1983.

(1955-1956). "De uma questão preliminar a todo tratamento possível da psicose"

In: . Escritos. Rio de Janeiro, Jorge Zahar Editor, 1998.

. (1960). "Posição do inconsciente": In: Escritos. Rio de

Janeiro, Jorge Zahar Editor, 1998.

. (1962-1963). O Seminário, Livro 10: A Angústia. Rio de Janeiro: Jorge Zahar Editor, 2005. 
(1964). LACAN, J. O Seminário, Livro 11: Os quatro conceitos fundamentais da psicanálise. 2. ed. Rio de Janeiro, Jorge Zahar Editor, 1998.

. LACAN, J. (1967a). Petit discours aus psychiatres de Sainte-Anne. Disponível em: < http://ecole-lacanienne.net/wp-content/uploads/2016/04/1967-11-10.pdf > . Acesso em 01 de outubro de 2019.

(1967b). “Alocução sobre as psicoses da criança". In:

Outros escritos.

Rio de Janeiro: Jorge Zahar Editor, 2003. p.359-368.

LIMA, Fernanda. Sobre um tratamento psicanalítico da psicose. In: Psicanálise, Universidade e Sociedade. CALDAS, Heloísa e ALTOÉ, Sônia (org.). Rio de Janeiro: Cia. de Freud, 2011.

. (1968). "Discurso de clausura de las jornadas sobre psicoses infantil" In:

MANONNI, M et al. Psicosis infantil. Buenos Aires: Nueva Visión, 1980.

(1971). "Lituraterra". In: . Outros Escritos. Rio de Janeiro, Zahar

Editor, 2001.

. (1971-1972). Le Seminaire, Livre 19bis: Le Savoir du psychanalyste. Disponível em: <http://gaogoa.free.fr/>. Acesso em: 18 de maio de 2016.

. (1972) “O aturdito". In: . Outros escritos. Rio de Janeiro: Jorge Zahar

Ed., 2003. p. 448-497.

. (1972-3). O seminário, livro 20: Mais, Ainda 2. ${ }^{\circ}$ ed. Rio de Janeiro, Jorge Zahar Editor, 1985.

(1973-1978) "Excursus". In: . Italia. (Italie). Sic transcrição do discurso registrado por Lomberto Boni e Sciana Loaldi. Milão: Editora Salamandra, 1978. . (1974). “A Terceira”. In: . Intervenciones y textos 2. Buenos Aires.

Manantial.

. (1975) "Conferencia en Ginebra sobre el Sintoma". In:

Intervenciones y textos, n.2, Buenos Aireas: Manantial, 1988.

(1975). "Conferencia en Ginebra sobre el Sintoma". In:

Intervenciones y textos, $n .2$, Buenos Aireas, Manantial, 1988. Tradução de Rogina Dias Coelho dos Santos e Viviane Antunes. Cópia reprográfica. In Escola Letra freudiana.

. (1975-1976). "Conference et entretiens dans des universités nordamericaines". In: Scilicet. n. ${ }^{\circ}$ 6/7, Paris, Seuil. . (1975-1976). O seminário, livro 23: O Sinthoma Rio de Janeiro, Jorge Zahar Editor, 2007. 
. (1976-77). Le séminaire, Livre 24. L'insu que sait de l'une bévue s'aile à mourre Inédito. Tradução de Jairo Gerbase disponível em: <campopsicanalitico.com.br>. Acesso em 18 de maio de 2016.

MALEVAL, Jean-Claude. “'Sobretudo Verbosos' os autistas” (2007). In: Latusa: Escola Brasileira de Psicanálise: Objetos soletrados no corpo, n. 12, Rio de Janeiro: Ed. Contracapa, 2007.

MALISKA, Maurício. A voz na psicanálise. Curitiba: Juruá, 2015.

MANDIL, Ram. Efeitos da letra: Lacan leitor de Joyce. RJ/BH: Ed. Contracapa. UFMG, 2003.

MATTOS-AVRIL, Renata. A voz e a invocação para musicar a vida ressonâncias entre música e psicanálise. 2011. Tese (Doutorado em Pesquisa e Clínica em Psicanálise) - UERJ, Rio de janeiro, 2011.

MUÑOZ, Nuria. Inventar o amor: um desafio na clínica das psicoses. 2005. Tese (Doutorado em teoria Psicanalítica) - UFRJ, Rio de Janeiro, 2005.

PORGE, Erik. “O inapanhável objeto do savoir-faire na análise”. In: Estudos da psicanálise. Belo Horizonte/MG. n.40. dez. pp. 49-62. 2013

STEVENS, Alexandre. “A clínica psicanalítica em uma instituição para crianças”. In: Estilos da Clínica. Revista sobre a infância com problemas. n.1. São Paulo: IP/USP, 1996.

SOLER, Colette. O inconsciente a céu aberto na psicose. Rio de Janeiro: Jorge Zahar Editor, 2002.

VIVÉS, Jean-Michel. "Pulsion invocante et destins de la voix". In: Paris: Navarrain. Tradução de Francisco R. de Farias. Revisão de Denise Maurano. 2009a

. "O silêncio das sereias de Kafka: Uma aproximação literária da voz como objeto pulsional”. Revista da Pós-Graduação em Literatura Portuguesa da UERJ: O MARRARE. n.11. 2009b.

A voz na clínica psicanalítica. Rio de Janeiro: Contra Capa/Corpo Freudiano Seção Rio de Janeiro. 2012.

. “A voz na psicanálise”. In: Reverso. Belo Horizonte. Ano 35. n. 66. Dez. 2013 


\title{
The Voice IN The Psychoanalytical Treatment Of The Psychosis
}

\begin{abstract}
This article has for objective to think about the specificity of the psychoanalytical treatment of the psychosis through the know-how with lalangue which shows the articulation between letter and voice. Therefore, it will be presented the premise that the voice is the cause and the effect of the subject by the logical operations of the alienation ant the separation. It will be also worked another way of thinking the structuring of the subject based on the articulation between language, lalangue and letter. Thus, it will be verified the particularly relation of the psychotic subject with the voice as an object a.
\end{abstract}

KEYWORDS: Psychoanalysis; Psychosis; Treatment; Object; Voice. 


\section{La Voix Dans Le Suivi Psychanalytique Des Psychoses}

\section{RÉSUMÉ}

Cet article a pour objective réfléchir à la spécificité du suivi psychanalytique de la psychose à partir du savoir-faire avec lalangue qui met en scène l'articulation entre lettre et voix. Ainsi il sera présenté la prémisse de la voix comme cause et effet du sujet et cela à partir de la constitution du sujet par les opérations logiques d'aliénation et de séparation. II sera également travaillé une nouvelle façon de penser à la structuration du sujet basé sur l'articulation entre langage, lalangue et lettre. Cela pour vérifier la particulière relation su sujet psychotique avec la voix en tant qu'objet a.

MoTS-CLÉS: Psychanalyse ; Psychoses; Suivi Analytique; Objet; Voix; 
Fernanda Mara da Silva Lima

RECEBIDO EM 24-09-2019

APROVADO EM 24-10-2019

(C) 2019 Psicanálise \& Barroco em revista

http://www.seer.unirio.br/index.php/psicanalise-barroco/index

revista@psicanaliseebarroco.pro.br

Programa de Pós-Graduação em Memória Social — UNIRIO

Memória, Subjetividade e Criação

www.memoriasocial.pro.br/proposta-area.php 